\title{
The Success Factors of Implementing Web-Based Gamification According to the Viewpoint of Female English Teachers for Public Education Stages
}

\author{
Thoraya Aldahash and Abdulhameed Alenezi
}

\begin{abstract}
Currently, one of the main concerns among teachers is to prepare a generation that emulates the knowledge society, and has the ability to keep pace with the renewed global changes; during creating socially interactive and constructivist learning environments such as gamified environments. The implementation of gamification in education needs to be carefully designed, which assures the importance of investigating the factors affect its use in education. Thus, this study aims to identify the factors that influence the success of applying web-based gamification in the educational process using a questionnaire adopted from the GAMEX scale. A total of 249 female English teachers participated in this study. To achieve the aims of this research, the researcher used the analytical descriptive method. The results showed that the most effective factors in the success of applying web-based gamification were entertainment, engagement, comprehension, creative thinking and the absence of a negative effect.
\end{abstract}

Index Terms-Success factors, web-based gamification, GAMEX scale, English teachers.

\section{INTRODUCTION}

Our world is currently witnessing increasing progress in information and communication technology, which affects different aspects of human life, including education. This pushes education to face a real challenge to keep pace with this technological development and participate in its making. This change forces educational institutions to offer solutions to benefit from that development and employ it in the educational structure, in line with its goals and axioms. It also forces these institutions to present the initiative to benefit from technology for raising the outputs of the educational process. Whereas integrating technology in the teaching and learning process is no longer a luxury, it becomes a vital requirement for developing educational structures, as technology provides a qualitative leap in reformulating the curriculum in its comprehensive sense and raising the level of educational output with less effort and better quality [1].

As an inevitable result of this development, many technological innovations have appeared in the field of education, and they have the attention of scholars and educators to achieve the maximum benefit of improving the educational process. Indeed, the use of technological innovations in education has been shown to change the interactions of teachers from individual teaching to organized and collaborative team teaching [2].

Manuscript received April 26, 2021; revised June 28, 2021.

The authors are with Jouf University, AlJouf, Saudi Arabia (e-mail: thoraya3430@gmail.com, ar.alenezi@ju.edu.sa).
Therefore, educational institutions have to change their traditional educational environments to newer educational methods, such as gamification-based educational environments. Gamification-based education is considered one of the newest trends in instructional technology. Because it prompts the learner, while presenting the information, to interact with the educational materials, and with other learners, in educational situations dominated by purposeful activity, gamification also develops communication skills, and interaction with the surrounding environment will increase the ability of the learner for creativity and creative expression. Gamification also provides the learner with the freedom to express himself in a socially acceptable framework that is enjoyable for himself and those around him [3]. Therefore, gamification is considered a promising method for using great motivational potential to attract students in classrooms with high efficiency. Thus, many educators see digital games as powerfully motivating digital environments [4], [5], because of their potential to enhance student engagement and motivation in learning [6], as well as an effective way to create socially interactive and constructivist learning environments [7].

The basic idea of gamification is employing this motivational ability of games for other purposes, not just related to the entertainment purposes of the game itself [8]. Using different games strategies in educational environments are not something new; however, the concept and implementation of gamification in the educational sector have been introduced very recently [9]. Mosa [10] emphasized that gamification is not a real game, but it employs play elements, designs, foundations, ideas, principles and mechanics in learning situations to motivate learners and involve them in the learning experience or to establish an effective and enjoyable learning environment for learners. Therefore, gamification offers a unique opportunity to combine teaching the content, literacy, and learning skills in the twenty-first century in a very attractive educational environment, whereas students today are very interested in games, which are often in virtual worlds, which calls for taking advantage of these worlds as an attractive motivation for students. This corresponds to their preferences and interests in a way that contributes to the achievement of educational goals [11].

Many studies have confirmed the importance of using gamification in education, and its effect on students' motivation and engagement, such as the study of Flores [12] and the study of Maloney [13] which confirmed the effectiveness of gamification as a method for learning English as a foreign language. Also, the study of Nah et al. 
[14] confirmed the effect of large and effective gamification in increasing learners' motivation and thus increasing their academic achievement. The study of Mejia [15] also indicated that the use of gamification through digital applications contributes to the integration of learners in the learning process and their attraction to learn more, in addition to the possibility of learning in all circumstances. The study of Sauerland et al. [16] showed the effectiveness of gamification in developing motivation and trends towards learning. The study of Lee and Hammer [17] confirmed that gamification increases the educational awareness of learners and establishes an atmosphere between them that supports the spirit of fair competition, which leads to an increase in the productivity of learners, encourages continuous learning for life, and helps the teacher to follow up the achievements and progress of learners and to provide them with appropriate feedback.

The results of Rouse's study [18] also indicated an increase in motivation and achievement for the group that received gamification in a learning course. At the same time, the study of Retherford [19] showed that gamification is a powerful and effective educational tool capable of motivating English language learners and increasing the growth of their vocabulary. The study of Al-Tabakh [20] also showed the ability of gamification to develop programming skills and solve problems, and the authors recommended that gamification should be applied in different learning environments.

Gamification learning outcomes have produced mixed results over the years, creating controversy and doubts over its potential in education [21], [22]. Although the majority of previous studies confirmed the positive contributions of gamification in improving education, the results of the study of Boris and Laskowski [23] showed that the majority of the experimental group students failed in the last test, their attendance and their motivation to come to the classroom was higher, and volunteer assignments were greater. The cause of failure and decreased motivation may be attributed to the knowledge of students about their positions in the list, as they have accumulated enough success points, in addition to the difference in age between them. The study of Al-Rehily [24] did not find any differences in motivation between students in the experimental and control groups, and the findings of the study of Mese \& Dursun [25] agree with this result. The results of the study of Al-Rehily [24] might be attributed to the fact that the studied sample was female students who were about to graduate; hence, their level of motivation was low due to their desire to complete the courses. Moreover, the lack of a difference in motivation in the study of Mese and Dursun [25] may be attributed to the type of sample, since the students were new and did not have sufficient knowledge. Additionally, the study of Al-Nashiri [26] found superior performance in the control group, suggesting that gamification does not contribute to developing English language skills among secondary school students. The author attributed this result to the poor quality of the gamification method used by the teacher, the lack of virtual class time, the novelty of the English language course and the high academic level of the control group. This assures that the way the instructional content is presented is equally important in learning outcomes as it can lead to a decline in performance or knowledge and skills acquisition despite the increase in participation and effort [27]. A gamified learning environment needs to be carefully designed, especially around the gaming elements it utilizes and has explicit and clear instructions [28]. Otherwise, the students could get distracted from the learning goals [29], [30].

The growing popularity of gamification combined with studies' mixed results has further increased the need to explore the specific processes relating to education to figure out their impact [31]. Many literature reviews regarding gamification in education have been conducted to understand its impact on students' learning [32], [33]. However, contradicting results, implementation in different educational levels, the lack of specific assessment tools, the ad hoc use of gaming elements, and the general reports from scholars that more studies are required in this field reveal a gap in the literature.[34], [35].

Several researchers in gamification have indicated that many contextual factors affect its use in education, including the content related to the gamified activity and the population it is addressed and used [36]-[38], and also the psychological factors that mediate the learning outcomes. Parra-Gonzalez et al. [39] emphasized the necessity to study the factors affecting gamification in the primary and secondary stages, in addition to developing the scale of gamification trials. Parra-Gonzalez et al. [40] also stressed the importance of studying the difference between the factors of gamification in traditional and virtual education environments. In the same context, López-Belmonte et al. [41] recommended investigating the factors affecting the application of gamification in the lower educational stages and including the social factor in the study.

Despite the findings of previous studies that emphasize the importance of applying gamification in the educational environment [19], [42]-[44], some studies showed that gamification was ineffective [23]-[26], [45], which necessitates further research to assess the effectiveness of gamification in the educational environment. Additionally, whilst previous studies that applied playing experience scales (e.g., GAMEX, CMELAC and GAMEFUL QUEST) investigated the factors affecting the users' (students and/or faculty staff) experience of gamification [46]-[49], no previous studies have assessed the playing experience of students according to the viewpoint of teachers who are responsible for designing/ choosing the appropriate gamification environment. To fill in this knowledge gap, the present study developed a scale that measures students' gamification experience based on teachers' observations and assessed the success factors affecting the web-based gamification application. Thus, we can set the main question of this research as follows:

What are the factors of web-based gamification success, according to the viewpoint of female English teachers for public education stages in the Al-Jouf region?

From the main question, we have these questions:

1) What is the impact level of entertainment on the success of web-based gamification application according to the viewpoint of female English teachers for public education stages in the Al-Jouf region? 
2) What is the impact level of comprehension on the success of web-based gamification application according to the viewpoint of female English teachers for public education stages in the Al-Jouf region?

3) What is the impact level of creative thinking on the success of web-based gamification application according to the viewpoint of female English teachers for public education stages in the Al-Jouf region?

4) What is the impact level of psychological factors on the success of web-based gamification application according to the viewpoint of female English teachers for public education stages in the Al-Jouf region?

5) What is the impact level of engagement on the success of web-based gamification application according to the viewpoint of female English teachers for public education stages in the Al-Jouf region?

\section{REVIEW OF LITERATURE}

\section{Gamification}

Gamification was introduced in the last decade and has focused on many different fields, including education [50]. Gamification is defined as the application of game elements to non-game contexts [51]. Also, Gartner [52] defined it as the application of game mechanics and game design techniques to engage and motivate individuals to achieve their goals.

Ceker \& Izdamli [53] stated that using the gamification in education has several reasons to embrace, including:

- Modifying some boring work to more manageable entertainment.

- Turning hard work processes into more enjoyable tasks.

- Help to increase the concentrate more easily.

- Increasing the participation.

- Provide the motivation and satisfaction for business.

- Helping individuals to increase their using of media tools; In order to achieve some aims.

- Helping all the learners to be more active and to participate.

- Helping individuals to be more aware and having more ability to use media tools easily, in order to satisfy their needs.

The effective factors when applying the gamification:

Gamification research has progressed slowly in recent years, in terms of improved technologies and designing the gamification experiment. In practice, researchers perform many experiments and studies of this type, although they are limited to a set of classic elements, such as points, badges, or leaderboards, and at the same time researchers analyze, or theorize, about these types of experiments, without analyzing the actual effects of these experiences on the participants. So it can be said that educational research and practice diverge from one another [54]. Thus, it can be said that the early research on gamification lacked clear theoretical models, which made it impossible to explain why certain gaming techniques succeeded in specific environments, while others did not [55].

The literature about gamification provides many scales, that cover many aspects of the gaming experience, the most prominent of these scales is the immersion questionnaire [56] and it includes five factors of immersion, which are: Cognitive sharing, real-world separation, emotional sharing, challenge and control; and the scale of game interaction [57], which included four levels of participation in the game, namely: Indoctrination, flow, presence, and immersion, in addition to the scale of game experience [58], which included seven factors to the experience of the game, namely: Efficiency, sensual and imaginative immersion, flow, tension, challenge, negative influence and positive influence [59].

Although these scales are often used in games research, there are some limitations that limit their applicability in the context of gamification, including that they evaluate experiences related to simulation applications, as they are limited to the same aspect, and are not generalizable to different contexts or applications, as well as it largely ignores the positive emotional traits of the play experience [59].

Although gamification is an important topic, but there is no suitable tool for measuring the emotional aspects and engagement in gamification which are represented by enjoyable experiences [60]. In spite of the emphasis on gaming experience, it is a poorly developed concept in gamification research, as there are only few contributions in this field, and they are all new, for example, Eppmann et al. [59] developed a model and scale for gamification experiment, creating a list of elements that were extracted from 22 research papers, with the aim of describing the scales of game experience metrics [48], these factors are: entertainment, comprehension, motivation, creative thinking, absence of negative impact, and control[59]. These main dimensions are related to the participants' experience with activities and environments of gamification, which are; Entertainment, Comprehension, Creative thinking, Activation, Absence of negative effect and Dominance [61].

Hogberg et al. [48] also introduced the Gameful Quest Scale, a tool used to measure the user's individual playing experience in systems and services, and it can also be used for adaptive gamification, within gamification contexts. The factors affecting the gamification experience in this scale are; Challenge, Achievement, Competition, Immersion, Social experiment, Entertainment and Directing [49].

Furthermore, in the same context; Baydas \& Cicek [46] confirmed the effectiveness and reliability of the scale of factors affecting gamification in university education, which includes six factors namely Impact of learning, Expected results, Competition, Entertainment, Participation and Intention. Moreover, Manzano - Leon et al. [49] also confirmed the influence of factors (i.e., Motivation, Learning, Flow, and Teamwork) included in the CMELAC scale, which measures students' perception of cooperative play learning strategies in the educational context.

Landers et al. [62] defined the playing experience through three psychological characteristics that lead to the success of such experiences when focusing on them, namely:

1) Realizing that goals are important and achievable.

2) Desire to pursue these goals, even if under restrictive rules, and the user is willing to abide by them.

3) Thinking that participation in play is voluntary.

The research of Kalogiannakis et al. [31] has confirmed 
the importance of finding frameworks in implementing the gamification in science education where this study tries to contribute to particularly in education field.

Moreover, the research of Papadakis [63] has evaluated the combined use of App Inventor and a game-development approach in school lessons and showed a positive effect on students' basic programming skills achievements and motivation in a teaching courses.

\section{METHODS}

The researcher used the survey descriptive method to achieve the aims of the study, which is relevant to the current research.

\section{The Population and Sample of the Study}

1) The population of the study consisted of all female English teachers in the Al-Jouf region for general education stages. There were 540 female teachers, according to the records of the Department of Education in the Al-Jouf region, during the academic year 2021.

2) The researcher distributed the study tool to all members of the population study. Then, she obtained 249 questionnaires from the members at a rate of $46.1 \%$.

3 ) Regarding the variable of educational stage, there were 97 teachers $(39.0 \%)$ for the primary stage, $82(32.9 \%)$ for the middle stage, and $70(28.1 \%)$ for the secondary stage. Regarding the variable of years of teaching experience, there were 24 teachers $(9.6 \%)$ with less than five years of experience, 106 teachers $(42.6 \%)$ with from 5 to 10 years of experience, and 119 teachers $(47.8 \%)$ with more than 10 years of experience. There were 235 teachers $(94.4 \%)$ with a bachelor's degree and 14 teachers $(5.6 \%)$ with higher academic qualifications.

\section{INSTRUMENTS}

The instruments have been developed by adopting the GAMEX scale Eppmann et al. [59], and it was used after legalizing it and verifying the validity of the translation through reverse translation. The current study adopted five dimensions and replaced the activation dimension by engagement. The questionnaire included two sections where the first section contained demographic data about the study sample (academic qualification, years of experience, educational stage) and the second section contained the five dimensions (i.e., success factors of applying web-based gamification).

The number of terms of the scale in its initial image is 28 , with 22 positive terms and 6 negative terms. The dimensions are divided as follows:

1) The factor of entertainment contains five terms.

2) The factor of comprehension contains five terms.

3) The factor of creative thinking contains six terms.

4) The factor of engagement contains six terms.

5) The factor of absence of negative effect contains six terms.

The five-point Likert scale, which ranges from "1" strongly disagree to " 5 " strongly agree, was used as shown in Table I.
TABLE I: THE FIVE-POINT LIKERT SCALE, Which RANGES From “1” STRONGLY DisAGREE TO "5" STRONGLY AGREE

\begin{tabular}{lccccc} 
& $\begin{array}{l}\text { Strongly } \\
\text { agree }\end{array}$ & Agree & Neutral & Disagree & $\begin{array}{c}\text { Strongly } \\
\text { disagree }\end{array}$ \\
\hline Positive & 5 & 4 & 3 & 2 & 1 \\
\hline Negative & 1 & 2 & 3 & 4 & 5 \\
\hline
\end{tabular}

\section{A. Validity of Instrument}

\section{1) Face validity}

Face validity is the validity based on the opinions of the arbitrators. The researcher presented the questionnaire in its initial form to 8 arbitrators who are specialists in the field of study (arbitrator names and specializations are shown in Appendix (3), and they were asked to study the questionnaire and express their opinions on it according to the extent of the convenience of the terms and their ability to achieve the objectives of the study; their comprehensiveness; the diversity of their content; the appropriateness of each term for the dimension to which it belongs; the evaluation of the level of linguistic formulation; the output; and any observations the arbitrators deem appropriate regarding the amendment, change, or deletion of terms. The amendments of arbitrators were adopted according to their suggestions, resulting in the face or logical validity of the questionnaire.

\section{2) Internal consistency validity}

The internal consistency validity of the terms of the questionnaire was calculated after applying the terms to an exploratory sample consisting of 18 teachers:

- Pearson correlation coefficient between the degree of each term and the total degree of the dimension to which it belongs (Table II).

- Pearson correlation coefficient between the degree of each dimension and the total degree of the questionnaire (Table III).

It is clear from Table II that the values of the correlation coefficients between all the terms and the total degree of the dimension to which each statement belongs are statistically significant at the indicator level of less than 0.01 , which indicates the coherence of these terms and their validity for application in the study sample.

Table III shows that the values of the correlation coefficients between the degree of 4 dimensions and the total degree of the questionnaire are statistically significant at the indicator level of less than (0.01) and that the value of the correlation coefficient between the degree 1 dimension and the total degree of the questionnaire is statistically significant at the indicator level less than 0.05 , which indicates the coherence of these dimensions and their suitability for application in the study sample.

\section{3) Discriminant validity}

The discriminant validity of the questionnaire was calculated according to the following steps:

The role of discriminant validity is to identify the extent of the effectiveness of the questionnaire in discriminating between the results of the two sides of the exploratory sample. The coefficient of discrimination was calculated by following the following steps:

- Arranging the responses of female teachers to the questionnaire in descending order.

- Dividing the female teachers according to the total degree of the questionnaire into three types: high 
(27\%), low (27\%), and middle (46\%).

- Defining the number of female teachers in each type according to the above percentages as follows: high ( 5 female teachers), low (5 female teachers), and middle (8 female teachers).

- Using a t-test for independent groups to compare the high and low types. The results are shown in Table IV.

Table IV indicates that there are significant differences at the indicator level of $\alpha \leq 0.05$ between the high and low types of the exploratory sample, as all levels of indication for all dimensions and for the questionnaire as a whole are less than 0.05 , which indicates the discriminant validity of the questionnaire.

\section{B. Emotional Intensity}

The emotional intensity was calculated for each term of the questionnaire. The emotional intensity was considered acceptable for the term if the percentage of those who responded to the alternative (neutral) was less than $25 \%$. Table V illustrates these results.

It is clear from Table $\mathrm{V}$ that all the percentages of those who responded to the alternative (neutral) for each of the statements of the questionnaire were less than $25 \%$, which indicates that all of the terms have an acceptable emotional intensity.

\section{Reliability of the Instrument}

The reliability of the questionnaire was verified by the Cronbach's alpha equation, and Table VI shows the results.

TABLE II: PEARSON CORRELATION COEFFICIENT BETWEEN THE DEGREE OF EACH TERM AND THE TOTAL DEGREE OF THE DIMENSION TO WHICH IT BELONGS

\begin{tabular}{|c|c|c|c|c|c|c|c|c|c|}
\hline absence of negative effect & the number & creative thinking & the number & motivation & the number & comprehension & the number & entertainment & the number \\
\hline $0.728 * *$ & 1 & $0.792 * *$ & 1 & $0.885 * *$ & 1 & $0.904 * *$ & 1 & $0.744 * *$ & 1 \\
\hline $0.887 * *$ & 2 & $0.810 * *$ & 2 & $0.887 * *$ & 2 & $0.870 * *$ & 2 & $0.708 * *$ & 2 \\
\hline $0.901 * *$ & 3 & $0.846^{* *}$ & 3 & $0.930 * *$ & 3 & $0.859 * *$ & 3 & $0.861 * *$ & 3 \\
\hline $0.910^{* *}$ & 4 & $0.858 * *$ & 4 & $0.906^{* * *}$ & 4 & $0.919 * *$ & 4 & $0.761 * *$ & 4 \\
\hline $0.764 * *$ & 5 & $0.955 * *$ & 5 & $0.824 * *$ & 5 & $0.840 * *$ & 5 & $0.808 * *$ & 5 \\
\hline $0.825^{* *}$ & 6 & $0.933 * *$ & 6 & $0.889 * *$ & 6 & & & & \\
\hline
\end{tabular}

TABLE III: PEARSON CORRELATION COEFFICIENT BETWEEN THE DEGREE OF EACH DiMENSION AND THE TOTAL DEGREE OF THE QUESTIONNAIRE

\begin{tabular}{|c|c|c||}
\hline Coefficient of correlation & the dimension & the number \\
\hline \hline $0.755^{* *}$ & entertainment & 1 \\
\hline $0.778^{* *}$ & comprehension & 2 \\
\hline $0.520^{*}$ & motivation & 3 \\
\hline $0.489^{*}$ & creative thinking & 4 \\
\hline $0.811^{* *}$ & absence of negative effect & 5 \\
\hline$* *$ Statistically significant at the indicator level less than $(0.01)$ \\
\hline \multirow{2}{*}{ Statistically significant at the indicator level less than $(0.05)$} \\
\hline
\end{tabular}

TABLE IV: THE RESULTS OF T-TEST FOR INDEPENDENT GROUPS, TO IDENTIFY THE DIFFERENCES BETWEEN THE HIGH AND LOW TYPES OF THE EXPLORATORY

\begin{tabular}{|c|c|c|c|c|c|c|}
\hline \multicolumn{7}{|c|}{ SAMPLE } \\
\hline the field & type & number & Arithmetic mean & standard deviation & T value & indicator level \\
\hline \multirow{2}{*}{ entertainment } & high & 5 & 5.00 & 0.000 & 5.715 & 0.005 \\
\hline & low & 5 & 4.16 & 0.329 & & \\
\hline \multirow{2}{*}{ comprehension } & high & 5 & 5.00 & 0.000 & 6.674 & 0.003 \\
\hline & low & 5 & 3.60 & 0.469 & & \\
\hline \multirow{2}{*}{ motivation } & high & 5 & 5.00 & 0.000 & 4.296 & 0.013 \\
\hline & low & 5 & 3.90 & 0.573 & & \\
\hline \multirow{2}{*}{ creative thinking } & high & 5 & 4.93 & 0.149 & 6.254 & 0.000 \\
\hline & low & 5 & 3.70 & 0.415 & & \\
\hline \multirow{2}{*}{ absence of negative effect } & high & 5 & 3.83 & 0.773 & 3.523 & 0.008 \\
\hline & low & 5 & 2.37 & 0.519 & & \\
\hline \multirow{2}{*}{ the whole questionnaire } & high & 5 & 4.75 & 0.168 & 8.650 & 0.000 \\
\hline & low & 5 & 3.55 & 0.263 & & \\
\hline
\end{tabular}




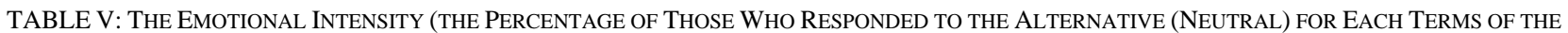
QUESTIONNAIRE'S TERMS)

\begin{tabular}{|c|c|c|c|c|c|c|c|c|c|c|c|c|c|c|}
\hline \multicolumn{2}{|c|}{$\begin{array}{c}\text { absence of } \\
\text { negative effect }\end{array}$} & \multirow{2}{*}{$\begin{array}{c}\text { the } \\
\text { number }\end{array}$} & \multicolumn{2}{|c|}{ creative thinking } & \multirow{2}{*}{$\begin{array}{c}\text { the } \\
\text { number }\end{array}$} & \multicolumn{2}{|c|}{ motivation } & \multirow{2}{*}{$\begin{array}{c}\text { the } \\
\text { number }\end{array}$} & \multicolumn{2}{|c|}{ comprehension } & \multirow{2}{*}{$\begin{array}{c}\text { the } \\
\text { number }\end{array}$} & \multicolumn{2}{|c|}{ entertainment } & \multirow{2}{*}{$\begin{array}{c}\text { the } \\
\text { number }\end{array}$} \\
\hline$\%$ & $\begin{array}{c}\text { Neutral } \\
\text { repetition } \\
\end{array}$ & & $\%$ & $\begin{array}{c}\text { Neutral } \\
\text { repetition } \\
\end{array}$ & & $\%$ & $\begin{array}{c}\text { Neutral } \\
\text { repetition }\end{array}$ & & $\%$ & $\begin{array}{c}\text { Neutral } \\
\text { repetition }\end{array}$ & & $\%$ & $\begin{array}{c}\text { Neutral } \\
\text { repetition }\end{array}$ & \\
\hline $16.7 \%$ & 3 & 1 & $5.6 \%$ & 1 & 1 & $0.0 \%$ & 0 & 1 & $16.7 \%$ & 3 & 1 & $0.0 \%$ & 0 & 1 \\
\hline $16.7 \%$ & 3 & 2 & $5.6 \%$ & 1 & 2 & $5.6 \%$ & 1 & 2 & $5.6 \%$ & 1 & 2 & $5.6 \%$ & 1 & 2 \\
\hline $16.7 \%$ & 3 & 3 & $5.6 \%$ & 1 & 3 & $5.6 \%$ & 1 & 3 & $11.1 \%$ & 2 & 3 & $0.0 \%$ & 0 & 3 \\
\hline $16.7 \%$ & 3 & 4 & $16.7 \%$ & 3 & 4 & $11.1 \%$ & 2 & 4 & $11.1 \%$ & 2 & 4 & $0.0 \%$ & 0 & 4 \\
\hline $16.7 \%$ & 3 & 5 & $5.6 \%$ & 1 & 5 & $5.6 \%$ & 1 & 5 & $5.6 \%$ & 1 & 5 & $5.6 \%$ & 1 & 5 \\
\hline $16.7 \%$ & 3 & 6 & $11.1 \%$ & 2 & 6 & $16.7 \%$ & 3 & 6 & & & & & & \\
\hline
\end{tabular}

TABLE VI: THE COEFFICIENT OF RELIABILITY OF QUESTIONNAIRE BY CORNBACH ALPHA EQUATION

\begin{tabular}{|c|c|c|c||}
\hline $\begin{array}{c}\text { the } \\
\text { number }\end{array}$ & the dimension & $\begin{array}{c}\text { number of } \\
\text { terms }\end{array}$ & $\begin{array}{c}\text { Cronbach } \\
\text { Alpha }\end{array}$ \\
\hline \hline 1 & entertainment & 5 & 0.824 \\
\hline 2 & comprehension & 5 & 0.922 \\
\hline 3 & motivation & 6 & 0.941 \\
\hline 4 & $\begin{array}{c}\text { creative thinking } \\
\text { absence of negative }\end{array}$ & 6 & 0.930 \\
\hline 5 & $\begin{array}{c}\text { effect } \\
\text { the whole } \\
\text { questionnaire }\end{array}$ & 28 & 0.915 \\
\hline
\end{tabular}

Table VI indicates that the reliability of the questionnaire according to Cronbach's alpha values for all dimensions of the questionnaire and for the whole questionnaire are statistically accepted. This is because the reliability coefficient is considered statistically accepted if its value is higher than 0.60 , which indicates the validity of the questionnaire for application in the study sample.

\section{RESUlTS}

To answer the first subquestion of the study, the researcher used the arithmetic means, standard deviations, arrangements, and levels of impact as shown in Table VII.

For the entertainment factor, the level of impact was very high for all the terms, and the arithmetic means of evaluation ranged from 4.20 to 5.00. Additionally, the whole dimension, which is related to the impact of entertainment on the success of applying web-based gamification according to the viewpoint of female English teachers for public education stages in the Al-Jouf region, had a very high impact, with an arithmetic mean of 4.57 .

To answer the second subquestion of the study, the researcher used the arithmetic means, standard deviations, arrangements, and levels of impact. For the comprehension factor, the level of impact was very high for all the terms, and the arithmetic means of evaluation ranged from 4.20 to 5.00. In the same way, the whole dimension, which is related to the impact of comprehension on the success of applying web-based gamification according to the viewpoint of female English teachers for public education stages in the Al-Jouf region, had a very high level of impact, with an arithmetic mean of 4.43 .

To answer the third subquestion of the study, the researcher used the arithmetic means, standard deviations, arrangements, and levels of impact. For the third factor, engagement, the level of impact was very high for all the terms, and the arithmetic means of evaluation ranged from 4.20 to 5.00. The whole dimension, which is related to the impact of engagement on the success of applying web-based gamification, had a very high level of impact with an arithmetic mean of 4.50 .

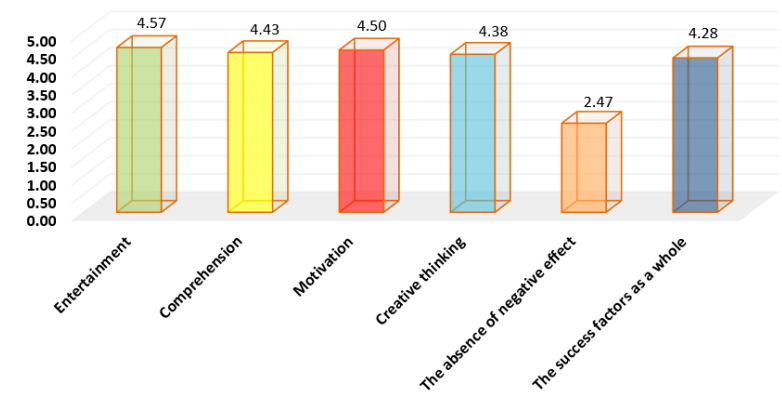

Fig. 1. The arithmetic means of success factors of applying web-based gamification according to the viewpoint of female English teachers for public education stages in the Al-Jouf region.

To answer the fourth subquestion of the study, the researcher used the arithmetic means, standard deviations, arrangements, and levels of impact. For the creative thinking factor, the level of impact was very high for all the terms, and the arithmetic means of evaluation ranged from 4.20 to 5.00. The whole dimension, which is related to the impact of creative thinking on the success of applying web-based gamification, had a very high level of impact, with an arithmetic mean of 4.38 .

To answer the fifth subquestion of the study, the researcher used the arithmetic means, standard deviations, arrangements, and levels of impact. For the fifth factor, the absence of a negative effect, the level of impact was medium for two of the terms, and the arithmetic means of evaluation ranged from 2.60 to 3.40. The level of impact was low for four of the terms, and the arithmetic means of evaluation ranged from 
1.80 to 2.60 . The whole dimension, which is related to the impact of the absence of a negative effect on the success of applying web-based gamification, had a low level of impact, with an arithmetic mean of 2.47 .

To answer the first main question of the study, the researcher used the arithmetic means, standard deviations, arrangements, and levels of impact (Table XII)

It is clear from Table XII and Fig.1 about the impact of applying web-based gamification that the level of impact was very high for four terms, and the arithmetic means of evaluation ranged from 4.20 to 5.00. The level of impact was low for 1 dimension, and the arithmetic means of evaluation ranged from 1.80 to 2.60 . The whole questionnaire, which is related to the factors of the success of applying web-based gamification according to the viewpoint of female English teachers for public education stages in the Al-Jouf region, had a very high arithmetic mean of 4.28 .

TABLE VII: THE ARITHMETIC MEANS, STANDARD DEVIATIONS, ARRANGEMENTS AND THE IMPACT'S LEVEL FOR THE TERMS OF FIRST DiMENSION

\begin{tabular}{||c|l|c|c|c|c||}
\hline \hline $\mathbf{m}$ & \multicolumn{1}{|c|}{ Term } & Mean & Deviation & Arrangement & Level of impact \\
\hline \hline 1 & I think that student likes learning through gamification & 4.53 & 0.596 & 4 & very high \\
\hline 2 & $\begin{array}{l}\text { I think that gamification-based learning contains the } \\
\text { entertainment and excitement for student. }\end{array}$ & 4.58 & 0.541 & 2 \\
\hline 3 & $\begin{array}{l}\text { I think that student feels happy when wins any game. } \\
\text { very high }\end{array}$ & 4.68 & 0.466 & 1 & 3 \\
\hline 5 & $\begin{array}{l}\text { I think gamification-based learning encourages the student on } \\
\text { competition. }\end{array}$ & 4.57 & 0.572 & very high \\
\hline 5 & $\begin{array}{l}\text { I think the student initiates the participation in } \\
\text { gamification-based learning. }\end{array}$ & 4.51 & 0.590 & 5 & very high high \\
\hline & the total degree of the entertainment's dimension & 4.57 & 0.468 & very high \\
\hline
\end{tabular}

TABLE VIII: The ARITHMETIC MEANS, STANDARD DEVIATIONS, ARRANGEMENTS AND THE IMPACT'S LEVEL FOR THE TERMS OF SECOND DimENSION

\begin{tabular}{|c|c|c|c|c|c|}
\hline 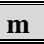 & Term & Mean & Deviation & Arrangement & Level of impact \\
\hline 1 & $\begin{array}{l}\text { I think using the gamification helps student to understand the } \\
\text { subject. }\end{array}$ & 4.42 & 0.643 & 3 & very high \\
\hline 2 & I think the student engages in the gamification based activities. & 4.51 & 0.547 & 1 & very high \\
\hline 3 & $\begin{array}{l}\text { I think that gamification-based learning contributes in } \\
\text { conveying information to the student. }\end{array}$ & 4.45 & 0.594 & 2 & very high \\
\hline 4 & $\begin{array}{l}\text { I think that gamification-based learning helps in achieving the } \\
\text { educational goals. }\end{array}$ & 4.35 & 0.704 & 5 & very high \\
\hline \multirow[t]{2}{*}{5} & $\begin{array}{l}\text { I think that gamification-based learning helps student in } \\
\text { increasing his level of mastering the skills of the lesson. }\end{array}$ & 4.42 & 0.644 & 4 & very high \\
\hline & The total degree of the comprehension's dimension & 4.43 & 0.569 & & very high \\
\hline
\end{tabular}

TABLE IX: THE ARITHMETIC MEANS, STANDARD DEVIATIONS, ARRANGEMENTS AND THE IMPACT'S LEVEL FOR THE TERMS OF THIRD DIMENSION

\begin{tabular}{|c|c|c|c|c|c|}
\hline $\mathbf{m}$ & Term & Mean & Deviation & Arrangement & Level of impact \\
\hline 1 & I think that the student is energetic while playing. & 4.58 & 0.570 & 1 & very high \\
\hline 2 & $\begin{array}{l}\text { I think that the concertation of the student increases with the } \\
\text { gamification based activities. }\end{array}$ & 4.53 & 0.641 & 3 & very high \\
\hline 3 & $\begin{array}{l}\text { I think that the gamification-based learning attracts the attention } \\
\text { of the student. }\end{array}$ & 4.55 & 0.647 & 2 & very high \\
\hline 4 & $\begin{array}{l}\text { I think that the gamification-based learning increases the } \\
\text { motivation of student toward learning. }\end{array}$ & 4.47 & 0.660 & 4 & very high \\
\hline 5 & $\begin{array}{l}\text { I think that gamification-based learning helps student in } \\
\text { increasing the positive reaction. }\end{array}$ & 4.47 & 0.684 & 5 & very high \\
\hline \multirow[t]{2}{*}{6} & $\begin{array}{l}\text { I think that the gamification-based learning encourages the } \\
\text { student to achieve the task. }\end{array}$ & 4.40 & 0.740 & 6 & very high \\
\hline & The total degree for the engagement as a whole & 4.50 & 0.587 & & very high \\
\hline
\end{tabular}

TABLE X: THE ARITHMETIC MEANS, STANDARD DEVIATIONS, ARRANGEMENTS AND THE IMPACT's LEVEL FOR THE TERMS OF FOURTH DiMENSION

\begin{tabular}{|c|c|c|c|c|c|}
\hline $\mathbf{m}$ & Term & Mean & Deviation & Arrangement & Level of impact \\
\hline 1 & $\begin{array}{l}\text { I think that the gamification-based learning allows the student to } \\
\text { play in creative ways. }\end{array}$ & 4.44 & 0.614 & 1 & very high \\
\hline 2 & $\begin{array}{l}\text { I think the student gets new information and thoughts, through } \\
\text { gamification-based learning. }\end{array}$ & 4.43 & 0.669 & 2 & very high \\
\hline 3 & $\begin{array}{l}\text { I think gamification-based learning widens the imagination of } \\
\text { the student. }\end{array}$ & 4.43 & 0.699 & 3 & very high \\
\hline 4 & $\begin{array}{l}\text { I think that the student can solve problems through } \\
\text { gamification-based learning. }\end{array}$ & 4.29 & 0.821 & 6 & very high \\
\hline 5 & $\begin{array}{l}\text { I think that the gamification-based learning develops the } \\
\text { innovation of the student. }\end{array}$ & 4.35 & 0.721 & 4 & very high \\
\hline \multirow[t]{2}{*}{6} & $\begin{array}{l}\text { I think that the student can express the subject in many ways } \\
\text { through gamification-based learning }\end{array}$ & 4.32 & 0.757 & 5 & very high \\
\hline & The total degree of the creative thinking's dimension & 4.38 & 0.636 & & very high \\
\hline
\end{tabular}


TABLE XI: THE ARITHMETIC MEANS, STANDARD DEVIATIONS, ARRANGEMENTS AND THE IMPACT'S LEVEL FOR THE TERMS OF FIFTH DiMENSION

\begin{tabular}{|c|c|c|c|c|c|}
\hline $\mathbf{m}$ & Term & Mean & Deviation & Arrangement & Level of impact \\
\hline 1 & $\begin{array}{l}\text { I think the student gets frustrated when she loses in the activities } \\
\text { of gamification. }\end{array}$ & 2.79 & 1.343 & 1 & medium \\
\hline 2 & $\begin{array}{l}\text { I think that the student feels disturbed during the activities of } \\
\text { gamification. }\end{array}$ & 2.28 & 1.107 & 5 & low \\
\hline 3 & $\begin{array}{l}\text { I think that the student feels nervous when she engages in the } \\
\text { activities of gamification for a long time. }\end{array}$ & 2.66 & 1.317 & 2 & medium \\
\hline 4 & $\begin{array}{l}\text { I think the environment of gamification make the student } \\
\text { nervous. }\end{array}$ & 2.36 & 1.184 & 4 & low \\
\hline 5 & $\begin{array}{l}\text { I think that the student feels afraid of failure during the activities } \\
\text { of gamification. }\end{array}$ & 2.58 & 1.268 & 3 & low \\
\hline \multirow[t]{2}{*}{6} & $\begin{array}{l}\text { I think the student feels that the activities of gamification are } \\
\text { waste of time. }\end{array}$ & 2.16 & 1.097 & 6 & low \\
\hline & The total degree of the psychological factors's dimension & 2.47 & 1.081 & & low \\
\hline
\end{tabular}

TABLE XII: The Arithmetic Mean, Standard Deviation, ArRanging And Evaluation the Degree For the Factors of Success of Web-Based GAMIFICATION

\begin{tabular}{|c|c|c|c|c|c||}
\hline \hline $\mathbf{m}$ & Dimension & Mean & Deviation & Arrangement & level of impact \\
\hline \hline 1 & entertainment & 4.57 & 0.468 & 1 & very high \\
\hline 2 & comprehension & 4.43 & 0.569 & 3 & very high \\
\hline 3 & engagement & 4.50 & 0.587 & 2 & very high \\
\hline 4 & creative thinking & 4.38 & 0.636 & 4 & very high \\
\hline 5 & absence of negative effect & 2.47 & 1.081 & 5 & low \\
\hline 9 & total degree for success factors & 4.28 & 0.526 & & very high \\
\hline
\end{tabular}

\section{DISCUSSION}

The study sample's responses, related to the level of impact of the entertainment factor, show that the level of impact was very high for all the terms, and the arithmetic means of evaluation ranged from 4.20 to 5.00. The related factors were represented by the dimension of entertainment and are arranged as illustrated in Table VII. The whole dimension, which is related to the impact of entertainment on the success of applying web-based gamification according to the viewpoint of female English teachers for public education stages in the Al-Jouf region, had a very high level of impact, with an arithmetic mean of 4.57 .

The study sample's responses illustrate that entertainment is one of the effective factors in the success of applying new educational techniques, such as gamification, which reflects the importance of concentrating on entertainment-based design to attract female students and achieve the aims of learning. While the results confirmed that entertainment is an important factor that affects the successful and effective application of gamification in the educational environment, it is possible to explain this result through the fact that female teachers are aware that the educational system requires the availability of factors creating positive emotions that support the learning of its members and increase their learning efficiency and achievement and that using attractive educational applications that can stimulate female students in the educational situation to achieve educational aims is important.

The results of the current research, regarding the level of the effect of entertainment in the application of gamification, agree with the results of the study of Parra Gonzales \& Segura [64] that the entertainment factor attains very high values due to its importance in building a successful educational environment based on gamification. The results are also in agreement with the study of Ayden [65] in the positive impacts of gamification, whereas this study confirms that the factor of entertainment affects not only the educational attitude but also the intention to continuously use gamification.

The study sample's responses related to the second subquestion of the study, which is the impact of comprehension, explain that the level of impact was very high for all the terms, and the arithmetic means of evaluation ranged from 4.20 to 5.00. The factors related to the dimension of comprehension are represented in the order illustrated in Table VIII The whole dimension, which is related to the impact of comprehension, has a very high level of impact, with an arithmetic mean of 4.43 .

The results of this research indicate that comprehension is an important factor influencing the effective application of gamification, because high levels of impact for the comprehension factor in the application of gamification were observed. This result is in line with the results of many studies that confirm the importance of comprehension and its role in the successful and effective application of gamification as a method of learning [41]. In contrast, the study of Parra-Gonzales \& Segura [64] found unclear results regarding this dimension. The researcher attributed the lack of clarity of the results to the style of formulating the terms, which calls for the need to reconsider the terms. This limitation negates the contradiction of the results of this study with the results of previous studies, which thereby confirms the role of comprehension in the effective application of gamification, and highlights the need for good preparation of the scales to properly achieve in accurate manner the results 
for which they were designed.

The results related to the impact of engagement showed that the level of impact was very high for all the terms, and the arithmetic means of evaluation ranged from 4.20 to 5.00. The factors related to the dimension of engagement are represented in the order as shown in Table IX The whole dimension, which is related to the impact of engagement on the success of applying web-based gamification according to the viewpoint of female English teachers for public education stages in the Al-Jouf region, has a very high level of impact, with an arithmetic mean of 4.50 .

Similar to the results of this research, which showed high levels of influence of the engagement factor in the application of gamification in educational environments, the results of the study of Parra-Gonzales \& Romero et al. [40] confirmed high levels of engagement for the participants, as students are more active and thus more engaged, which helps them learn. The study of Lopez-Pelmont et al. [41] also showed positive results in stimulation and motivation. In contrast, the results of the study of Hanus \& Fox [45] demonstrated a decrease in motivation and engagement during the use of gamification-based educational environments, and the authors recommended the importance of caution when applying some gamification methods in educational environments.

The results of this research related to the impact of creative thinking showed that the level of impact was very high for all the terms, and the arithmetic means of evaluation ranged from 4.20 to 5.00. The factors related to the dimension of creative thinking are arranged in Table X. The whole dimension, which is related to the impact of creative thinking on the success of applying web-based gamification according to the viewpoint of female English teachers for public education stages in the Al-Jouf region, has a very high level of impact, with an arithmetic mean of 4.38 .

The results of this research related to the impact of creative thinking are consistent with the results of the study of Parra-Gonzales \& Romero et al. [40], as well as the study of Parra-Gonzales, Gómez-Barajas et al. [66], that creative thinking has very high impact values due to it having a positive effect on students in the environments of gamification and being a skill that must be available among learners. The high level of impact for the creative thinking factor in applying gamification is consistent with the results of Al-Juhani's study [42], which demonstrated the effectiveness of gamification learning through the blackboard to develop problem-solving skills. In addition, Al-Jaraiwi [43] demonstrated the effectiveness of learning through gamification in developing high thinking skills, including creative thinking skills.

The results related to the fifth subquestion of the study, the level of impact of the absence of a negative effect, showed that the level of impact was medium for two of the terms, and the arithmetic means of evaluation ranged from 2.60 to 3.40 . The level of impact was low for four of the terms, and the arithmetic means of evaluation ranged from 1.80 to 2.60 . The factors that are related to this dimension are represented in the order as explained in Table XI. The whole dimension, which is related to impact level of the factor of absence of negative effect on the success of applying web-based gamification according to the viewpoint of female English teachers for public education stages in the Al-Jouf region, has a low level of impact, with an arithmetic mean of 2.47.

The study sample's responses in the current research showed that there are no negative and undesirable effects when applying gamification in educational environments. This emphasizes the necessity of choosing/designing applications or educational practices based on gamification, taking into account the support of positive aspects, and avoiding any negative effects that may hinder the success of the application or the achievement of goals. Whereas the results of the study of Eppmann et al. [59] confirm that the presence of entertainment alone is not enough, negative feelings must be excluded to establish the gamification trial in a high-quality manner, as the high levels of the effect of the gamification trial are associated with strong entertainment value, in addition to the absence of negative feelings.

The results of this research related to decreasing the level of impact of the factor of an absence of negative effect agree with the findings of the study of Parra-Gonzales, Gómez-Barajas, et al. [66] that the absence of a negative effect has low impact values. As that study confirmed that negative influences do not exist or are almost nonexistent, in the gamification trial, and in the same context, the study of Lopez-Pelmont et al. [41] confirmed the presence of positive results related to the absence of a negative effect factor.

The results related to the main question of the study showed that the level of impact was very high for four terms, and the arithmetic mean of evaluation ranged from 4.20 to 5.00. The level of impact was low for 1 dimension, and the arithmetic mean of evaluation ranged from 1.80 to 2.60. The effective factors in the success of gamification are arranged in order as illustrated in Table XII and Fig. 1.

The whole questionnaire, related to the factors of success, has a very high level with an arithmetic mean of 4.28. The researcher thinks that presenting the educational material in a way that attracts the students' attention and based on enjoyment ensures that they are motivated to learn, engaged in its stages, and then learn the skill. The results regarding the main question of this research - whether entertainment is the most important factor in applying gamification - confirm this hypothesis.

The results of this research regarding the factors affecting the application of gamification are in line with the results of the study of Eppmann et al. [59], whereas entertainment is the most effective factors in the success of gamification. Moreover, there is an agreement that the high levels of impact and positive feelings regarding the application of gamification are strongly associated with entertainment and the absence of negative emotions.

The researcher thinks that the results of this study are generally in agreement with motivation theory. The theory indicates that gamification-based educational environments focus on individual motives, represented by various internal emotions, and extrinsic motives, represented by using the elements of gamification. This is to increase the participation, engagement and motivation of the learner, who engages in the activities of gamification, enjoys the completion of the tasks assigned to him, and possibly converts external motives into internal motives if he finds the tasks enjoyable. These 
results are also consistent with constructivist theory by assisting the learner in developing problem-solving skills, with the active and effective participation of the learner, in building knowledge by himself. In the same context, flow theory contributes to promoting active participation, engagement and effective learning. This is one of the important theories influencing the application of gamification in education.

\section{LIMITATIONS}

This study contains a number of limitations that can, in turn, provide opportunities for further research, including the following:

- The researcher used the descriptive method in the study, so the experimental aspect can support the results of exploration in future research.

- The study was only administered in the Al-Jouf region; therefore, it should be conducted in other regions and the related results should be compared to improve the generalization ability of the results.

- The study sample contained female teachers; therefore, a similar study should be conducted in the future to measure the factors affecting the application of gamification according to the viewpoint of female students in the stages of public and academic education.

- A similar study should also be done in the future to measure the factors affecting the application of gamification in university education according to the viewpoint of faculty members.

\section{CONCLUSION}

According to the current research, gamification success factors scale is a powerful tool for designing interactive learning environments in the new educational era. Its power can assist educators in drawing important conclusions about its impact on learning outcomes. Prior to the implementation of gamification in the classroom teachers need to determine the needs and interests of them and their students, as well as what they wish to achieve. So, in order for gamification to be successfully implemented, the key factors identified coherently ensure the effective implementation of gamification for students' participation and success. This paper uncapped the critical success factors to consider in its' Implementation. The most effective factors in the success of web-based gamification are arranged, according to their importance, as follows: entertainment, engagement, comprehension, creative thinking and the absence of a negative effect. The conversation about gamification posits that this approach when used in the classroom in a correct way could be an effective tool for increasing student learning and engagement, compared to the traditional lecture format.

\section{CONFLICT OF INTEREST}

The authors declare no conflict of interest.

\section{AUTHOR CONTRIBUTIONS}

TA designed, conducted the research, analyzed the data, wrote original draft and reviewed/edited the manuscript; AA conceptualized the project, supervised the research and reviewed/edited the manuscript. Both authors approved the final version.

\section{REFERENCES}

[1] W. S. Al-Halfawi, Educational Technology Innovations in the Information Age (2nd edition), Dar Al-Fikr for publishing and distribution, 2006.

[2] J. Sandholts, C. Ringstaff, and D. C. Dwyer, "The relationship between technological innovation and collegical interaction," Apple Computer, 1991.

[3] H. M. Al-Mawali, Education in the Age of Informatics, University Book House, Al Ain, 2011.

[4] S. Papadakis, M. Kalogiannakis, V. Orfanakis, and N. Zaranis, "The appropriateness of Scratch and App Inventor as educational environments for teaching introductory programming in primary and secondary education, ” Int. J. Web Based Learn. Teach. Technologies, vol. 12 , no. 4, pp. 58-77, 2017.

[5] S. Papadakis, M. Kalogiannakis, V. Orfanakis, and N.Zaranis, "Novice programming environments. Scratch \& App Inventor: A first comparison," in Proc. the 2014 Workshop on Interaction Design in Educational Environments, New York, 2014.

[6] C.-Y. Hsu, M.-J. Tsai, Y.-H. Chang, and J.-C. Liang, "Surveying in-service teachers' beliefs about game-based learning and perceptions of technological pedagogical and content knowledge of games," Educ. Technol. Soc., vol. 20, no. 1, pp. 134-143, 2017.

[7] K. Y. G. Chan, S. L. Tan, K. F. T. Hew, B. G. Koh, L. S. Lim, and J. C. Yong, "Knowledge for games, games for knowledge: designing a digital roll-and-move board game for a law of torts class," Res. Pract. Technol. Enhanced Learn, vol. 12, no. 1, p. 7, 2017.

[8] K. M. Kapp, The Gamification of Learning and Instruction: Game-Based Methods and Strategies for Training and Education, John Wiley \& Sons, 2012.

[9] D. O. Göksün and G. Gürsoy, "Comparing Success and Engagement in Gamified Learning Experiences via Kahoot and Quizizz," Computers \& Education, vol. 135, pp. 15-29, 2019.

[10] M. A. F. Musa, "Play Mechanics and Dynamics: A procedural framework for understanding fun design principles in education,' Egyptian Association for Educational Technology, vol. 30, no. 7, pp. 3-18, 2020.

[11] T. L. Kingsley and M. M. Grabner-Hagen, "Vocabulary by gamification," The Reading Teacher, vol. 71, no. 5, pp. 545-555, 2018.

[12] J. Figueroa-Flores, "Using gamification to enhance second language learning," Digital Education Review, vol. 21, pp. 32-5, 2015.

[13] S. Maloney, "Gamification in English language teaching: More than child's play," English for ASIA, 2019.

[14] F. Nah, V. Telaprolu, S. Rallapalli, and P. Venkata, "Gamification of education," presented at the 15th International Conference, United States, 2013.

[15] J. Mejia, "Impact of gamification and shared situated displays on smartphone application engagement," Master Theses, Grand Valley State University, Grand Valley State University archieve, 2013.

[16] W. Sauerland, J. Broer, and A. Breiter, "Motivational impact of gamification for mobile learning of kanji," presented at the e-Media World Conference on Educational Media and Technology, 2015.

[17] J. J. C. U. Lee and J. C. U. Hammer, "Gamification in Education: What, How, Why Bother?" Academic Exchange Quarterly, vol. 15, no. 2, pp. $1-5,2011$

[18] K. Rouse, "Gamification in science Education: The relationship of Educational Games to Motivation and Achievement," Doctoral thesis, The University of Southern Mississippi, 2013.

[19] T. A. Retherford, "The effects of gamification on english language learners' motivation and vocabulary growth," Master Theses, Southeast Missouri State University, 2020.

[20] H. A. I. Al-Tabakh and A. T. A. Ismail, "Designing a learning environment based on the interaction between the "competitive / cooperative" digital game stimulus pattern and the "single / multiple" challenge level and its impact on developing programming skills and problem solving among educational technology students," The Educational Journal, no. 77, pp. 259-361, 2020. 
[21] Z. Zainuddin, "Students' learning performance and perceived motivation in gamified flipped-class instruction," Computers \& Education, vol. 126, pp. 75-88, 2018.

[22] K. Berkling and C. Thomas, "Gamification of a software engineering course and a detailed analysis of the factors that lead to its failure," in Proc. the 2013 International Conference on Interactive Collaborative Learning, Kazan, Russia, 2013.

[23] M. Borys and M. Laskowski, "Implementing game elements into didactic process: A case study," presented at Knowledge and Learning International Conference, Zadar, Croatia, 2013.

[24] T. A. Al-Rahili, "The effectiveness of a participatory, multi-media learning environment based on gamification in developing the achievement and motivation of Taibah University students," Journal of the Islamic University for Educational and Psychological Studies, vol. 26, no. 6, pp. 53-83, 2018.

[25] C. Mese and O. Dursun, "Effectiveness of gamification elements in blended learning environments," Turkish Online Journal of Distance Education, vol. 20, no. 3, pp. 119-142, 2019.

[26] F. A. A. Al-Nashiri, "The role of gamification in developing English language skills among secondary school students in Jeddah," Virtual International Conference on the Future of Digital Education in the Arab World, Knowledge Enrichment for Conferences and Research, Taif. 2020.

[27] H.-Y.n Huang and D. A. Soman, "Practitioner's guide to gamification of education," Research Report Series Behavioural Economics in Action, University of Toronto, Canada, 2013.

[28] D. Strmečki, A. Bernik, and D. Radošević, "Gamification in e-learning: Introducing gamified design elements into e-learning systems," Journal of Computer Science, vol. 11, pp. 1108-1117, 2015.

[29] H. M. Huang, U. Rauch, and S. S. Liaw, "Investigating learners' attitudes toward virtual reality learning environments: Based on a constructivist approach," Computers \& Education, vol. 55, pp. $1171-1182,2010$.

[30] K. Ijaz, A. Bogdanovych, and T.Trescak, "Virtual worlds vs. books and videos in history education," Interactive Learning Environments, vol. 25, pp. 904-929, 2017.

[31] M. Kalogiannakis, S. Papadakis, and A. I. Zourmpakis, "Gamification in science education. A systematic review of the literature," Education Sciences, vol. 11, no. 1, p. 22, 2021.

[32] S. Subhash and E. A. Cudney, "Gamified learning in higher education: A systematic review of the literature," Computers in Human Behavior, vol. 87, pp. 192-206, 2018.

[33] Z. Zainuddin, S. K. W. Chu, M. Shujahat, and C. J. Perera, "The impact of gamification on learning and instruction: A systematic review of empirical evidence," Educational Research Review, vol. 30, 2020.

[34] J. Hamari, J. Koivisto, and H. Sarsa, "Does gamification work? - A literature review of empirical studies on gamification," in Proc. of the Annual Hawaii International Conference on System Sciences, Waikoloa, USA, 2014

[35] A. Rapp, F. Hopfgartner, J. Hamari, C. Linehan, and F. Cena, "Strengthening gamification studies: Current trends and future opportunities of gamification research," Int. J. Hum. Comput. Stud., vol 127 , pp. 1-6, 2019

[36] J. Hamari and J. Koivisto, "Social motivations to use gamification: An empirical study of gamifying exercise," in Proc. the ECIS 2013: 21st European Conference on Information Systems, Utrecht, The Netherlands, 2013.

[37] J. Koivisto and J. Hamari, "Demographic differences in perceived benefits from gamification," Computers \& Human Behavior, vol. 35 , pp. 179-188, 2014.

[38] S. Deterding, "The lens of intrinsic skill atoms: A method for gameful design," Human-Computer Interaction, vol. 30, no. 3-4, pp. 294-335, 2015.

[39] M. A. Parra-Gonzálezy and A. Segura-Robles, "Translation and validation of the gameful experience scale (Gamex)," Pedagogy Magazine, vol. 71, no. 4, pp. 87-99, 2019.

[40] M. A. Parra-Gonzalezy, A. Segura, and C. Romero, "Analysis of creative thinking and levels of student activation after a gamification experience," Educar, vol. 56, no. 2, pp. 475-489, 2020.

[41] J. López-Belmonte, A. Segura-Robles, A. Fuentes-Cabrera, and M. E. Parra-González, "Evaluating activation and absence of negative effect: Gamification and escape rooms for learning," International Journal of Environmental Research and Public Health, vol. 17, no. 7, 2020.

[42] Z. M. S. Al-Juhni, "The effect of gamification's learning through the blackboard to develop problem-solving skills in mathematics among talented students in the first grade of secondary school," Journal of Scientific Research in Education, vol. 11, no. 19, pp. 643-666, 2018
[43] S. S. M. Al-Jerawi, "The impact of learning by web-based gamification on the development of academic achievement and creative thinking among elementary school students," Journal of the Association of Arab Universities for Education and Psychology, vol. 17, no. 3, pp. 17-54, 2019.

[44] J. Watson-Huggins, "An experimental study on the effects of a gamified software intervention in mathematics achievement among sixth grade students (publication No. 2461136222)," Doctoral Dissertation, Nova Southeastern University, The Free Library, 2018.

[45] M. D. Hanus and J. Fox, "Assessing the effects of gamification in the classroom: a longitudinal study on intrinsic motivation, social comparison, satisfaction, effort, and academic performance," Computers \& Education, vol. 127, no. 80, pp. 152-161, 2015.

[46] O. Baydas and M. Cicek, "The examination of the gamification process in undergraduate education: A scale development study," Technology, Pedagogy and Education, vol. 28, no. 3, pp. 269-285, 2019.

[47] M. E. Parra-González, A. Segura-Robles, and E. R. Gómez-Barajas, "Assessing gamified experiences in physical education teachers and students," International Journal of Educational Research and Innovation, no. 13, pp. 166-176, 2020.

[48] J. Högberg, J. Hamari, and E. Wästlund, "Gameful experience questionnaire (GAMEFULQUEST): An instrument for measuring the perceived gamefulness of system use," User Modeling and User-Adapted Interaction, vol. 29, no. 3, 2019.

[49] A. Manzano-Leó et al., "Development and validation of a questionnaire on motivation for cooperative playful learning strategies," International Journal of Environmental Research and Public Health, vol. 18, no. 3, pp. 1-10, 2021.

[50] G. Richter, D. R. Raban, and S. Rafaeli, Studying Gamification: The Effect of Rewards and Incentives on Motivation, Gamification in Education and Business, Springer, 2015

[51] L. Bond, "Mathimagicians quest: applying game design concepts to education to increase school engagement for students with emotional and behavioral disabilities," Doctoral Dissertation, University of Washington, 2015

[52] B. Burke, "Gartner redefines gamification," Gartner, 2014.

[53] E. Ceker and F. Izdamli, "What "Gamification" is and what it's not," European Journal of Contemporary Education, vol. 6, no. 2, pp. 221-228 2017

[54] R. Hopfgartner, H. Linehan, anf Cena, "Strengthening gamification studies: Current trends and future opportunities of gamification research," International Journal of Human-Computer Studies, vol. 127, pp. 1-6, 2018

[55] R. N. Landers and A. K. Landers, "An empirical test of the theory of gamified learning: The effect of leaderboards on time-on-task and academic performance," Simulation y Gaming, vol. 45, no. 6, pp. $769-785,2014$

[56] C. Jennett et al., "Measuring and defining the experience of immersion in games," International Journal of Human-Computer Studies, vol. 66 no. 9, pp. 641-661, 2008.

[57] J. Brockmyer, C. Fox, and K. Curtiss, "The development of the game engagement questionnaire: A measure of engagement in video game-playing," Journal of Experimental Social Psychology, vol. 45, no. 4, pp. 624-634, 2009.

[58] K. Poels, Y. Kort, and W. A. IJsselsteijn, "Game Experience Questionnaire: Development of a self-report measure to assess the psychological impact of digital games," Technische Universiteit Eindhoven, 2007.

[59] R. Eppmann, M. Bekk, and K. Klein, "Gameful experience in gamification: Construction and validation of a gameful experience scale [GAMEX]," Journal of Interactive Marketing, vol. 43, pp. 98-115, 2018

[60] H. Kai and J. Hamari, "A Definition for Gamification: Anchoring Gamification in the service marketing literature," Electronic Markets, vol. 27 , no. 1, pp. 21-31, 2017 .

[61] M. A. Parra-Gonzálezy and A. Segura-Robles, "Translation and validation of the gameful experience scale (Gamex)," Pedagogy Magazine, vol. 71, no. 4, pp. 87-99, 2019.

[62] M. Parra-Gonzales and A. Segura-Robles, "Analysis of the gamified experiences of teachers and students of secondary education," ESPACIOS, vol. 40, no. 23, p. 15, 2019.

[63] S. Papadakis, "Evaluating a game-development approach to teach introductory programming concepts in secondary education," International Journal of Technology Enhanced Learning, vol. 12, no. 2, pp. $127-145,2020$

[64] M. Parra-Gonzales and A. Segura-Robles, "Analysis of the gamified experiences of teachers and students of secondary education," ESPACIOS, vol. 40, no. 23, p. 15, 2019. 
[65] G. Aydin, "Adoption of gamified systems: A study on a social media gamification website," International Journal of Online Marketing, vol. 5, no. 3, 2015.

[66] M. E. Parra-González, A. Segura-Robles, and E. R. Gómez-Barajas, "Assessing gamified experiences in physical education teachers and students," International Journal of Educational Research and Innovation, no. 13, pp. 166-176, 2020.

Copyright $\odot 2021$ by the authors. This is an open access article distributed under the Creative Commons Attribution License which permits unrestricted use, distribution, and reproduction in any medium, provided the original work is properly cited (CC BY 4.0).

Thoraya Saad Aldahash received the master's degree in instructional technology from College of Education, Instructional Technology department at Al Jouf University in 2021, which is located in Al Jouf, Saudi Arabia. She is currently an English teacher at the 1st Elementary school, Domat AlJandal. Her research interests include educational technology. Thoraya Aldahash is a member at Atta Digital Initiative.
Abdulhameed Rakan Alenezi is an associate professor in instructiona technology, Ph.D from Utara University of Malaysia in 2011. He obtains a master degree in information technology in education \& training from Wollongong University, Australia in 2007. The major field of research is e-learning and ict.

He is a head of Instructional Technology Department at Jouf University, Saudi Arabia. Previously he worked as a dean of Computer \& Information Science College and as the Dean of engineering college. He has many research and studies listed in well recognized journals

Dr. Alenezi is a member of many international associations and journals editor including The North American Simulation and Gaming Association (NASAGA).USA, International Forum of Educational Technology \& Society (IEEE Technical Committee on Learning Technology), Pittsburgh E-Learning Society, the Canadian Institute of Distance Education Research CIDER, Journal of American Academic Research. San Francisco, CA, USA. 